\title{
Creutzfeldt-Jakob disease associated with peripheral neuropathy
}

\author{
Mario Casmiro* \\ Unit of Neurology, Ospedale per gli Infermi, Azienda USL della Romagna, Faenza, Italy
}

Received: September 26, 2015

DOI: $10.5430 /$ crim.v3n1p 12
Accepted: November 8, $2015 \quad$ Online Published: November 25, 2015

URL: http://dx.doi.org/10.5430/crim.v3n1p12

\begin{abstract}
We describe the case of a patient with sporadic Creutzfeldt-Jakob disease (sCJD) with associated peripheral neuropathy and discuss the literature on this topic. A patient with autopsy proven CJD presented with the clinical signs of a sensory (large fibres) polyneuropathy. The neurophysiologic study showed a sensory-motor polyneuropathy with predominant axonal pattern, without denervation signs. Peripheral neuropathy may be associated with CJD but the significance of such association is yet undefined; it may accompany or even precede the onset of clinical picture of CJD and there is no unique electrophysiological pattern. In the few investigated cases no prion protein (PrP) deposits have been found in the peripheral nerves, whereas PrP deposits have been detected in some dorsal root ganglia neurons. In conclusion, the frequency of peripheral neuropathy in CJD could be currently underestimated. The peripheral nervous system should be thoroughly investigated in all cases of CJD in order to share light on the significance of this association. Our case also reminds of the usefulness of CSF neuron-specific enolase determination in the early stage of CJD as an easily available diagnostic tool.
\end{abstract}

Key Words: Creutzfeldt-Jakob disease, Neuron-specific enolase, Neuropathy, Cerebrospinal fluid

\section{INTRODUCTION}

Creutzfeldt-Jakob disease (CJD) is a fatal neurodegenerative disease characterized by deposition of an abnormal isoform of prion protein $\left(\mathrm{PrP}^{\mathrm{SC}}\right)$ causing severe alterations (neuronal loss, astrocytosis, spongiform changes) in the cortical and subcortical gray matter. Involvement of the peripheral nervous system in CJD has been described in several cases, ${ }^{[1-3,5-11]}$ but the relationship between CJD and peripheral neuropathy is uncertain. Here we report a further case of sporadic CJD associated with peripheral neuropathy and discuss the literature.

\section{Presentation of Case}

A 72-year-old man was evaluated in August 2002 because of a subacute onset of dizziness, headache and imbalance.
The neurological examination showed absent deep tendon reflexes with loss of vibration sensation in the lower limbs, ataxia (worsened by eye closure) and bradykinesia; tremor, rigidity and pin prick sensation alteration were absent; plantar responses were flexor. His past history was negative for corneal transplantation, growth hormone injection and neurosurgical interventions; he was not a blood donor and he never received blood transfusions. His family history was negative. A brain MRI showed small areas of increased signal intensity on T2 sequences (centrum semiovale, caudate and putamen of both sides); a brain SPECT was normal. The neuropsychological evaluation (Mental Deterioration Battery) showed a pathologic value (-0.897, corrected for age and schooling; normal value: $\geq 0$ ), indicative of slight cognitive impairment. Chest X-ray and blood analysis were normal.

\footnotetext{
${ }^{*}$ Correspondence: Mario Casmiro; Email: mcasmiro@hotmail.com; Address: Unit of Neurology, Ospedale per gli Infermi, Azienda USL della Romagna, Faenza, Italy.
} 
The patient was readmitted to the hospital two months later because of a subacute deterioration of mental status, with memory impairment, ideomotor slowing and confusion. At neurological examination he was disoriented, his speech was slow and dysarthric and his facial expressions was decreased (hypomimia). Myoclonic jerks were present in upper and lower limbs at rest and increased during attempts at voluntary movement. Distal pseudoathetosis was present in upper limbs during posture maintaining, with a muscle strength evaluation of 4/5 MRC in proximal lower limbs, without atrophy; deep tendon reflexes were decreased in upper limbs and absent in the legs and vibration sensation was now abolished in both lower limbs. Gait was wide based and unsteady. Dysmetria, more pronounced on the right side, was present. At this stage only a qualitative neuropsychological assessment could be performed, which showed a marked alteration of attentive functions and control ability, ideomotor slowing, slow speech and difficulty in word finding, often leaving sentences incomplete, confusion and tendency to fall asleep. Laboratory investigation showed normal results of routine exams (serum blood glucose, blood cell count, blood urea nitrogen and creatinine, total proteins and protein electrophoresis, electrolytes, thyroid hormones, cholesterol, triglycerides, TPHA). To rule out other possible causes for the peripheral neuropathy the following other exams were performed, all of which gave normal results: serology for HIV, HCV, cytomegalovirus and borrelia, antinuclear, antinDNA, anti-extractable nuclear antigens, anti-mitochondrial, smooth muscle and parietal cell antibodies; vitamin B12, PSA, carbohydrate antigen 19-9, and cryoglobulins. Homocysteine was slightly elevate $(20 \mu \mathrm{mol} / \mathrm{ml}$; normal values $4-15)$ whereas folic acid was slightly reduced $(2.0 \mathrm{ng} / \mathrm{ml}$, normal values 2.5-17.0). Esophagogastroduodenoscopy showed hiatal hernia with slight chronic atrophic gastritis (HP-); the search for Whipple disease was negative.

EEG changes over time, from October 10 to December 6 are shown in the Figure 1. The first exam (A) shows a well structured background activity with superimposed diffused, slow, isolated theta-delta activity, with alternating predominance. One month later (B) traces show a slower and less structured background activity, with diffused theta-delta activity. At the last examination, one month later (C), EEG shows a completely destructured and disorganized background activity, with superimposed abundant and diffuse theta-delta activity; a rapid and isolated activity, clinically corresponding to a myoclonic jerk, is recorded on the right frontal region. MR spectroscopy showed metabolic alterations within the striatum, medial thalamus and cerebellum indicative of severe neuronal loss associated with high grade gliosis. Metabolic alterations were absent in the occipital and parietal cortex.

Published by Sciedu Press

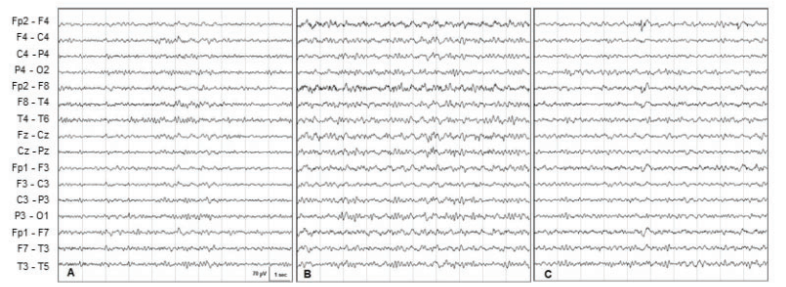

Figure 1. EEG changes over time: October, 10(A), November, 4(B) and December, 6(C)

\section{Peripheral nerve evaluation}

Electromyography of the lower limbs ( $\mathrm{R}$ and $\mathrm{L}$ medial head of gastrocnemius, $\mathrm{R}$ and $\mathrm{L}$ vastus lateralis, $\mathrm{R}$ tibialis anterior and $\mathrm{R}$ abductor digiti quinti) displayed an excess of high amplitude and polyphasic motor unit potentials in the $\mathrm{R}$ and $\mathrm{L}$ gastrocnemius, $\mathrm{L}$ quadriceps and $\mathrm{R}$ tibialis anterior, with an incomplete recruitment pattern; none showed spontaneous activity at rest. The sensory action potential of both sural nerves was not recordable; motor conduction velocities were $39 \mathrm{~m} / \mathrm{s}$ in both tibial nerves, and $39 \mathrm{~m} / \mathrm{s}$ in the L peroneal nerve, with normal distal latencies. F waves were delayed in the tibial nerves ( $57.6 \mathrm{~ms}$ on the right, $56.9 \mathrm{mg}$ on the left). The amplitude of the CMAP was reduced in both peroneal nerves.

\section{Cerebrospinal Fluid examination}

CSF examination (October 2002) showed normal cells, proteins (49) and glucose (65). Isoelettrofocusing showed a small oligoclonal component with serum correspondence (mirror, pattern 4); the search for anti-Borrelia antibodies (IgG and $\operatorname{IgM}$ ) was negative. Neuron specific enolase (NSE) evaluation showed marked elevation in the CSF $(185.0 \mathrm{ng} / \mathrm{ml}$; n.v. $<20 \mathrm{ng} / \mathrm{ml}$ ) whereas it was only marginally increased in the serum $(17.2 \mathrm{ng} / \mathrm{ml}$; n.v. $<15.5 \mathrm{ng} / \mathrm{ml})$. CSF testing for 14-3-3 protein revealed pathologic amounts.

Evolution: During the next two months the patient developed a progressive impairment of consciousness up to a vegetative state, with increased myoclonus. Death occurred in January 2003 because of respiratory failure from pneumonia.

Brian pathological findings: marked alterations (degeneration and neuronal loss, marked astroglial proliferation) are present in the cerebral and cerebellar cortex. Ultrastructural examination shows the presence of vacuoles within the cytoplasmatic processes of glial cells and within neuronal dendrites; absence of inflammatory response. Western Blot of cerebral tissue: presence of pathogen prionic protein (PrP-39). Anatomical diagnosis: subacute spongiform degeneration (classical Creutzfeldt-Jakob disease). 


\section{Discussion}

In this patient the peripheral neuropathy manifested at the onset of the clinical picture and was characterized by a predominant sensitive pattern; no other cause emerged from the laboratory investigations. The findings of the neurophysiologic study were indicative of a sensory-motor polyneuropathy with predominant axonal pattern, without denervation signs.

The association between CJD and peripheral neuropathy has been reported in several articles. Lope et al. ${ }^{[1]}$ described a case of acute ascending polyradiculoneuritis in the course of a case of SCJD, whose anatomical correlate was a demyelination of the nerve roots.

In a case of $\mathrm{fCJD}^{[2]}$ an electron-microscopic study of biopsied superficial peroneal nerve showed evidence of peripheral neuropathy in the absence of clinical evidence of neuropathy.

Sadeh et al..${ }^{[3]}$ referring to experimental data, ${ }^{[4]}$ consider the possibility that the sensory neurons of trigeminal ganglia could represent the route of CJD spread from periphery to the brain; they also considered the (remote) possibility of an immune response to the peripheral nerves by means of an indirect triggering.

In two patients of Lybian origin, immigrated in Israel at a young age, Neufeld et al. ${ }^{[5]}$ described a demyelinating neuropathy. In one patient the symptoms of neuropathy preceded CJD by 2 months, whereas in the second case prominent and diffuse fasciculations appeared at onset of the cognitive impairment. Nerve biopsy disclosed prominent and widespread segmental demyelination in this latter case (whereas it was unremarkable in the first one). Both patients had a codon 200 mutation and, notably, the second patient also had elevated titres of anti-GM1 antibodies.

Antoine et al. ${ }^{[6]}$ described a case of fCJD (Glu200Lys mutation) with associated peripheral neuropathy characterized by demyelination and remyelination predominant in the roots and proximal nerve trunks; the PrP27-30 could not detected in the peripheral nervous system.

Esiri et al.$^{[7]}$ reported a patient whose initial presentation was a painful sensory neuropathy; sequencing of PrP gene did not show mutations.

In a patient with SCJD (methionine-valine polymorphism at codon 129) Kovács et al ${ }^{[8]}$ described a demyelinating neuropathy associated with amyotrophy which preceded the onset of CJD by several months; PrP could not be detected in the peripheral nerves.

In a group of 16 consecutive patients with sporadic CJD Niewiadomska et al ${ }^{[9]}$ found 3 patients with clinical signs of peripheral nervous system involvement. Electrophysiological findings consistent with peripheral nervous system damage were present in these 3 patients and in other 11 patients ( $88 \%$ of the total sample); in the remaining $12 \%$ of subjects neuropathological examination revealed features of chronic disease of motor cells. The electrophysiological findings were variable, consistent with motor neuron disease (1 patient), polyneuropathy (5 patients) and mononeuritis multiplex (6 patients), axonal pattern ( 9 patients), and mixed axonal-demyelinating neuropathy (4 patients).

Ishida et al. ${ }^{[10]}$ in a group of 8 patients with necropsy confirmed prion diseases, detected abnormal PrP deposition occurring in the dorsal root ganglia and peripheral nerves of sporadic and dural graft associated CJD, but not in GertsmannSträussler-Scheinker disease. No correlation could be found between PrP deposits and the clinical features.

Zéphir et al. ${ }^{[11]}$ hypothesized a dying-back axonopathy or centrifugal dissemination of the PrP pathological process because of PrP deposits in the spinal posterior horn (with normal appearance of dorsal root ganglia).

In summary, analysis of currently available data shows that peripheral neuropathy may be associated with CJD, that it may precede ${ }^{[3,5,8,9]}$ CJD onset or it may appear simultaneously. ${ }^{[5,6]}$ Electrophysiological pattern may vary, though axonal neuropathy is by far the most common ${ }^{[9]}$ and both sensitive and motor component may be involved. Furthermore, in the largest series available ${ }^{[9]}$ mono-neuritis multiplex (37\%) and polyneuropathy $(31 \%)$ were the most common findings. A chronic course is the usual pattern, except for a single reported case of acute polyradicoloneuritis. ${ }^{[1]}$ At nerve biopsy, no PrP deposits were found in the peripheral nerves, ${ }^{[8,10]}$ whereas PrP deposits were detected in some dorsal root ganglia neurons of some but not all patients (specifically not in the patients with peripheral nerve signs). ${ }^{[10]}$ Finally, in patients with CJD plus neuropathy mutation of PrP gene was reported at codons $200,{ }^{[5,6]} 129,,^{[8,11]}$ and $102 .{ }^{[10]}$

Another relevant point raised by our case is represented by the markedly elevated CSF values of NSE. Similar findings have been previously reported. ${ }^{[12,13]}$ In a group of 58 patients with definite and probable CJD, Zerr and coll. reported significantly higher CSF NSE values compared to controls; a cut-off value of $35 \mathrm{ng} / \mathrm{ml}$ provided $80 \%$ sensitivity with $92 \%$ specificity for the diagnosis of CJD. ${ }^{[14]}$ However, it must be emphasized that because of progressive neuronal loss, CSF NSE values tend to fall into the normal range in the advanced stage of the disease. ${ }^{[12]}$ Reference values for CSF and serum NSE in a normal population have been published. ${ }^{[15]}$

ISSN 2332-7243 E-ISSN 2332-7251 


\section{Conclusion}

At present the role of peripheral neuropathy in CJD is not defined, however its true incidence could be underestimated. For this reason, provided that the clinical picture is compatible, the peripheral nervous system should be carefully investigated for the presence of a peripheral neuropathy in all patients with suspected CJD.
The increased CSF level of NSE, two months after the appearance of first symptoms, represents another relevant point of our case. Since it is a widely available test, CSF NSE determination could represent a useful additional test for the diagnosis of CJD, especially if performed early in the course of the disease. However, the interpretation of the result of this test in the advanced stages of the disease should be made with caution.

\section{REFERENCES}

[1] Lope ES, Junquera SR, Martinez AM, et al. Acute ascending polyradiculoneuritis in a case of Creutzfeldt-Jakob disease. J Neurol Neurosurg Psychiatry. 1977; 40(2): 149-155. PMid:325182 http://dx.doi.org/10.1136/jnnp.40.2.149

[2] Vallat JM, Dumas M, Corvisier N, et al. Familial CreutzfeldtJakob disease with extensive degeneration of white matter. Ultrastructure of peripheral nerve. J Neurol Sci. 1983; 61(2): 261-275. http://dx.doi.org/10.1016/0022-510X (83) 90010-2

[3] Sadeh M, Chagnac Y, Goldhammer Y. Creutzfeldt-Jakob disease associated with peripheral neuropathy. Isr J Med Sci. 1990; 26(4): 220-222. PMid:2161406

[4] Guiroy DC, Shankar SK, Gibbs CJ Jr, et al. Neuronal degeneration and neurofilament accumulation in the trigeminal ganglia in Creutzfeldt-Jakob disease. Ann Neurol. 1989; 25(1): 102-106. PMid:2643917 http://dx.doi.org/10.1002/ana.410250119

[5] Neufeld MY, Josiphov J, Korczyn AD. Demyelinating peripheral neuropathy in Creutzfeldt-Jakob disease. Muscle Nerve. 1992; 15(11): 1234-1239. PMid:1362595 http://dx.doi.org/10.1002/mus .880151103

[6] Antoine JC, Laplanche JL, Mosnier JF, et al. Demyelinating peripheral neuropathy with Creutzfeldt-Jakob disease and mutation at codon 200 of the prion protein gene. Neurology. 1996; 46(4): 1123-1127. PMid:8780103 http://dx.doi.org/10.1212/WNL . 46.4.1123

[7] Esiri MM, Gordon WI, Collinge J, et al. Peripheral neuropathy in Creutzfeldt-Jakob disease. Neurology. 1997; 48(3): 784. PMid:9065568 http://dx.doi.org/10.1212/WNL . 48.3.784

[8] Kovács T, Arányi Z, Szirmai I, et al. Creutzfeldt-Jakob disease with amyotrophy and demyelinating polyneuropathy. Arch Neurol. 2002; 59(11): 1811-1814. PMid:12433270 http://dx.doi.org/10.10 01/archneur.59.11.1811
[9] Niewiadomska M, Kulczycki J, Wochnik-Dyjas D, et al. Impairment of the peripheral nervous system in Creutzfeldt-Jakob disease. Arch Neurol. 2002; 59(9): 1430-1436. http://dx.doi.org/10.1001 /archneur.59.9.1430

[10] Ishida C, Okino S, Kitamoto T, et al. Involvement of the peripheral nervous system in human prion diseases including dural graft associated Creutzfeldt-Jakob disease. J Neurol Neurosurg Psychiatry. 2005; 76(3): 325-329. PMid:15716520 http://dx.doi.org/10.1136 /jnnp. 2003.035154

[11] Zéphir H, Stojkovic T, de Seze J, et al. Severe and rapidly evolving peripheral neuropathy revealing sporadic Creutzfeldt-Jakob disease. J Neurol. 2009; 256(1): 134-136. PMid:19219575 http: //dx.doi.org/10.1007/s00415-009-0037-9

[12] Wakayama Y, Shibuya S, Kawase J, et al. High neuron-specific enolase level of cerebrospinal fluid in the early stage of Creutzfeldt-Jakob disease. Klin Wochenschr. 1987; 65(16): 798-801. PMid:3309455 http://dx.doi.org/10.1007/BF01743256

[13] Evers S, Droste DW, Ludemann P, et al. Early elevation of cerebrospinal fluid neuron-specific enolase in Creutzfeldt-Jakob disease. J Neurol. 1998; 245(1): 52-53. PMid:9457631 http://dx.doi.o $\mathrm{rg} / 10.1007 / \mathrm{s} 004150050176$

[14] Zerr I, Bodemer M, Racker S, et al. Cerebrospinal fluid concentration of neuron-specific enolase in diagnosis of Creutzfeldt-Jakob disease Lancet. 1995; 345(8965): 1609-1610. http://dx.doi.org/10 $1016 / \mathrm{S} 0140-6736$ (95) $90118-3$

[15] Casmiro M, Maitan S, De Pasquale F, et al. Cerebrospinal fluid and serum neuron-specific enolase concentrations in a normal population. Eur J Neurol. 2005; 2: 369-374. PMid:15804267 http: //dx.doi.org/10.1111/j.1468-1331.2004.01021.x 